\title{
Combined Effects of Ethanol and Garlic on Hepatic Ethanol Metabolism in Mice
}

\author{
Ritsuko Kishimoto, ${ }^{1, *}$ Miwa Ueda, ${ }^{1}$ Hideyuki Yoshinaga, ${ }^{1}$ \\ Kiyoshi GODA ${ }^{1}$ and Song-Shin PARK ${ }^{2}$ \\ ${ }^{1}$ Faculty of Nutrition, Kobe Gakuin University, \\ Kobe 651-2180, Japan \\ ${ }^{2}$ Occupational Diseases Diagnosis and Research Center, \\ 34-6 Kusan-Dong, Pupyeong-ku, Inchon 403-120, Korea \\ (Received October 15, 1998)
}

\begin{abstract}
Summary The combined effects of ethanol and components in fresh garlic on ethanol metabolism were investigated in the livers of mice. Male, 11-wk-old $\mathrm{C} 3 \mathrm{H} / \mathrm{HeNCrj}$ mice were intragastrically administered $2 \mathrm{~g}$ ethanol $/ \mathrm{kg}$ body weight after being administered fresh garlic juice for $8 \mathrm{~d}$ (garlic group), and changes in the concentrations of ethanol, acetaldehyde and acetate in the serum, and changes in the activity of hepatic enzymes related to ethanol metabolism in mice were examined. The increases in the concentrations of acetaldehyde and acetate in the serum after ethanol administration tended to be diminished following garlic administration. The microsomal ethanol-oxidizing system (MEOS) in the livers of the garlic groups was significantly lower than that of the control microsomes at $2 \mathrm{~h}$ after ethanol administration. It therefore seems that the decrease of MEOS in hepatic microsomes caused a smaller increase in the acetaldehyde concentration in the serum of the garlic groups because cytosolic alcohol dehydrogenase showed no significant difference between the control and garlic groups. After ethanol administration, the content of cytochrome P-450 in the hepatic microsomes of the control groups increased, while that of the garlic groups did not change although cytochrome P-450 (CYP) 2E1 and $1 \mathrm{~A} 2$ in the hepatic microsomes of the garlic groups increased. These results indicate that the induction of isozymes of cytochrome P-450 other than CYP 2E1 and 1A2 was inhibited following garlic administration. Cytosolic high $\mathrm{Km}$ and total aldehyde
\end{abstract}

* To whom correspondence should be addressed. E-mail: kishimot@nutr. kobegakuin. ac.jp

Abbreviations: CYP, cytochrome P-450; ADH, alcohol dehydrogenase; AIDH, aldehyde dehydrogenase; MEOS, microsomal ethanol-oxidizing system; ANH, aniline hydroxylase; TAT, tyrosine aminotransferase; MAb, monoclonal antibody; DAS, diallyl sulfide; DADS, diallyl disulfide; DATS, diallyl trisulfide; DSF, disulfiram; DASO2, diallyl sulfine; DDTC, diethyldithiocarbamate. 
dehydrogenase $(\mathrm{AlDH})$ in the liver of the garlic groups tended to be lower than those activities of the control groups at 1 and $2 \mathrm{~h}$ after ethanol administration. It therefore seems that the decreases of $\mathrm{AlDH}$ in the hepatic cytosols diminished the increase of acetate in the serum of the garlic groups after ethanol administration. These results suggest that the ethanol metabolism in the mouse liver is controlled by components in fresh garlic juice.

Key Words $\mathrm{C} 3 \mathrm{H} / \mathrm{He}$ mice, garlic, ethanol, CYP 2E1, CYP $1 \mathrm{~A} 2$

Garlic (Allium sativum Linn.), which is widely used as a food or condiment, has been known since ancient times as a flavoring agent and for its medicinal properties. The major volatile compounds of garlic are sulfur-containing compounds (1-3). It has been reported that garlic oil inhibits tumor promotion (4) and that diallyl sulfide (DAS), an element of garlic flavor, inhibits chemical toxicity and tumorigenesis in mouse $8(5,6)$. It was also reported that DAS inhibited cytochrome P-450 (CYP) 2E1 in the rat liver $(7,8)$, whereas DAS and its metabolite diallyl sulfine (DASO2), and disulfiram (DSF) and its metabolite diethyldithiocarbamate (DDTC) induced CYP 2B1/2 $(9,10)$. It is known that CYP 2E1 is an ethanol inducible cytochrome P-450 (11) and catalyzes microsomal ethanol-oxidizing system (MEOS) activity in mammalian species (12). It has been also reported that CYP $2 \mathrm{E} 1$ in rat hepatic microsomes is an aldehyde oxidase (13). By the way, it is known that alcohol or food ingestion can profoundly affect the pharmacokinetics of administered drugs (14). It is also considered that the ingestion of alcohol with food can cause significant combined effects on the ethanol metabolism. The effect of fresh garlic on the ethanol metabolism in hepatic microsomes has not yet been reported. In the present study, we orally administered an ethanol solution to mice after preadministration of fresh garlic juice to investigate the combined effects of ethanol and components in garlic on the changes in the concentrations of ethanol, acetaldehyde and acetate in the serum, changes in the various enzymatic activities related to pathways of ethanol metabolism in the liver, and the induction of cytochrome P-450 isozymes in the hepatic microsomal fraction.

\section{EXPERIMENTAL}

Animals. Four-week-old male $\mathrm{C} 3 \mathrm{H} / \mathrm{HeNCrj}(\mathrm{C} 3 \mathrm{H} / \mathrm{He})$ mice were obtained from Japan Charles River. After they were housed for $6 \mathrm{wk}$, one group of the mice was given $0.1 \mathrm{~mL}$ garlic juice $/ \mathrm{d} /$ mouse intragastrically for $8 \mathrm{~d}$. Fresh garlic bulbs were purchased at a local retail supermarket in the Kobe area, grated using a grater and then placed in cotton gauze and pressed. About $50 \mathrm{~mL}$ of muddy juice accompanied with strong odor was extracted per $100 \mathrm{~g}$ of garlic bulbs, which was then diluted 5-fold with distilled water. This concentration was chosen because 7 mice receiving $0.1 \mathrm{~mL}$ of garlic juice diluted 0 or 3 -fold with distilled water grew markedly weak after $2 \mathrm{~d}$ and one of these mice died after $3 \mathrm{~d}$, while body weights 
of mice receiving 5-fold dilutions did not change compared with the controls. Brady et al (7) gave a dose of $200 \mathrm{mg}$ DAS in corn oil $/ \mathrm{kg}$ body weight to rats. However, DAS is a compound derived from garlic only at $30-100 \mu \mathrm{g} / \mathrm{g}$ of garlic (3). The garlic juice was prepared fresh daily prior to the experiment. Forty mice for each control and garlic-administered group were fed commercial MF food (Oriental Yeast) ad libitum during the experimental period. Mice were fooddeprived overnight at the end of this period, given $2 \mathrm{~g}$ of ethanol $/ \mathrm{kg}$ body weight intragastrically at 9:00 a.m., and then sacrificed by cervical dislocation after 1 (10 a.m.) or $2 \mathrm{~h}$ (11 a.m.). Mice not administered ethanol $(0 \mathrm{~h})$ were also sacrificed at the same time. The serum was collected immediately and prepared for assaying the concentrations of ethanol, acetaldehyde and acetate. The liver was also removed immediately and weighed to determine various enzyme activities. All samples were stored at $-70^{\circ} \mathrm{C}$ until use.

Cell fractions. Liver cell fractionation was performed by differential centrifugation as described previously $(15,16)$. Each fraction was kept at $-70^{\circ} \mathrm{C}$ until it was assayed for enzyme activity.

Determinations of ethanol, acetaldehyde and acetate concentrations in serum. Concentrations of ethanol, acetaldehyde and acetate in the serum were determined using a Blood Alcohol UV Test, F-kit Acetaldehyde or F-kit Acetate, respectively (Boehringer Mannheim Biochemica).

Measurements of enzyme activities. Tyrosine aminotransferase (TAT) activity in the cytosolic fraction was assayed by the method described by Granner and Tomkins (17). Cytosolic alcohol dehydrogenase (ADH) activity was assayed as described previously $(15,16)$. The activities of MEOS and aniline hydroxylase (ANH) in the microsomal fraction were assayed according to the method of Klein et al (18) and Brodie and Axelrod (19), respectively. The activities of aldehyde dehydrogenase $(\mathrm{AlDH})$ in the three cell fractions were assayed by the method of Lebsack et al (20), except that the acetaldehyde concentrations were $5 \mathrm{~mm}, 300 \mu \mathrm{M}$ and $50 \mu \mathrm{M}$ for total, high and low $\mathrm{Km}$ enzymes, respectively.

Immunoblot analysis. Western blotting was performed as described previously (16). Mouse monoclonal antibody (MAb) 1-98-1 to rat CYP 2E1 (21), mouse MAb 1-7-1 to rat CYP 1A1 and 1A2 (22), mouse MAb 1-31-2 to rat CYP 1A1 (22), and mouse MAb 2-66-3 to rat CYP 2B1 (23) were used as primary antibodies. A densitometric analysis of the bands after Western blotting was performed using an Image Master DTS (Pharmacia Biotech).

Other assay methods. Total microsomal cytochrome P-450 content was determined from the CO-reduced difference spectrum in $0.1 \mathrm{~m}$ potassium phosphate buffer (24). The protein contents in the cell fractions were measured by the biuret method (25) with bovine serum albumin (Sigma Chemical) as the standard.

Statistical analysis. Data were expressed as means \pm SE. The differences among values were analyzed using analysis of variance (ANOVA) coupled with Duncan's new multiple range test (26) and considered significant at $p<0.05$. 

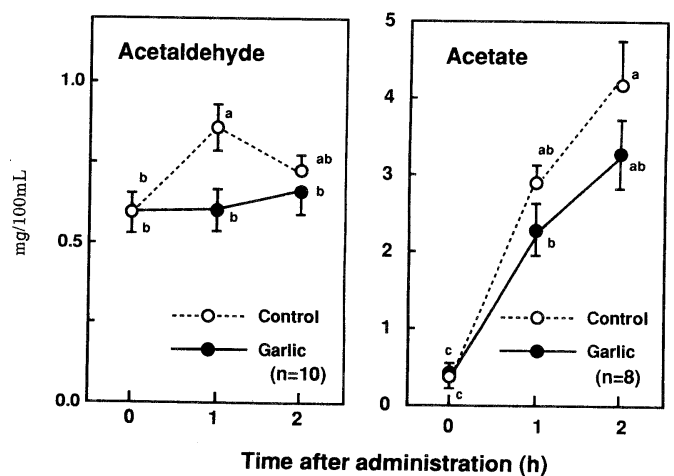

Fig. 1. Changes in concentrations of acetaldehyde and acetate in the serum of control and garlic groups after oral ethanol administration. Values (means \pm SE) not bearing the same superscript or subscript letters are significantly different from one another $(p<0.05)$. Among the experimental groups, the letter " $\mathrm{a}$ " indicates the highest value with descending order of " $b$ " and "c."

\section{RESULTS}

The weights of body and liver of the control groups $(27.3 \pm 0.5$ and $1.20 \pm 0.02 \mathrm{~g}$, respectively) and garlic groups $(27.2 \pm 0.4$ and $1.20 \pm 0.01 \mathrm{~g}$, respectively) were almost the same values after garlic administration.

Changes in the concentrations of ethanol, acetaldehyde and acetate in the serum

The concentration of ethanol in the serum of both the control and garlic groups showed a peak at $1 \mathrm{~h}(192 \pm 21$ and $199 \pm 50 \mathrm{mg} / 100 \mathrm{~mL}$, respectively) and then decreased at $2 \mathrm{~h}(138 \pm 21$ and $146 \pm 30 \mathrm{mg} / 100 \mathrm{~mL}$, respectively). Figure 1 shows the concentrations of acetaldehyde and acetate in the serum after ethanol administration. The concentration of acetaldehyde in the serum of the control group increased significantly at $1 \mathrm{~h}$ after ethanol administration and then decreased at $2 \mathrm{~h}$, while its concentration in the garlic groups tended to be slightly higher than in the control groups. The concentration of acetate in the serum of both groups was significantly increased at 1 and $2 \mathrm{~h}$ after ethanol administration. The increase of that in the garlic groups tended to be smaller than that in the control groups.

Activities of TAT and ADH in the hepatic cytosols

The activities of TAT and ADH in the hepatic cytosolic fraction showed no significant differences between the control and garlic groups (data not shown).

Activities of MEOS in the hepatic microsomes

Following the administration of garlic juice, the activity of MEOS did not change $(0 \mathrm{~h})$. After ethanol administration, the activity of MEOS in the garlic 


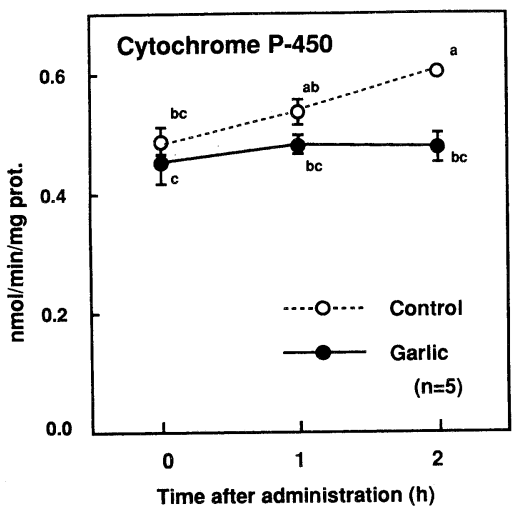

Fig. 2. Changes in content of cytochrome P-450 in the hepatic microsomal fractions of control and garlic groups after oral ethanol administration. Values (means $\pm \mathrm{SE}$ ) not bearing the same superscript or subscript letters are significantly different from one another $(p<0.05)$. Among the experimental groups, the letter " $\mathrm{a}$ " indicates the highest value with descending order of " $b$ " and "c."

groups at $2 \mathrm{~h}$ was significantly lower than that in the control groups (data not shown).

The content of cytochrome P-450 in the hepatic microsomes

As shown in Fig. 2, following the administration of garlic juice $(0 \mathrm{~h})$, the content of cytochrome P-450 tended to be low. The content of cytochrome P-450 in the control groups was significantly higher at $2 \mathrm{~h}$ than at $0 \mathrm{~h}$, while that in the garlic groups did not change significantly after ethanol administration.

\section{Activities of ANH in the hepatic microsomes}

Following the administration of garlic juice, the activity of ANH did not change $(0 \mathrm{~h})$ and, in the garlic groups, tended to be higher than that in the control groups 1 and $2 \mathrm{~h}$ after ethanol administration (data not shown).

\section{Immunoblot analysis of the hepatic microsomal proteins}

The detection of CYP 2E1 was carried out using MAb 1-98-1. As shown in Fig. 3A (upper panel), immunoreactive bands of CYP 2E1 were observed in all hepatic microsome preparations. The intensity of this band showed a 12 -fold increase following garlic administration $(0 \mathrm{~h})$ and also increased 6- and 9-fold in the control groups and 9- and 23-fold in the garlic groups at 1 and $2 \mathrm{~h}$ after ethanol administration, respectively (Fig. 3A, lower graph). The detection of CYP 1A1 and $1 \mathrm{~A} 2$ were carried out using MAb 1-7-1. One immunoreactive band of CYP 1A2 was also observed in all hepatic microsome preparations but CYP 1A1 was not detected in any hepatic microsomes (Fig. 3B, upper panel). Following garlic juice administration, the intensity of CYP $1 \mathrm{~A} 2$ was stronger (1.1-fold increase) than that 
A

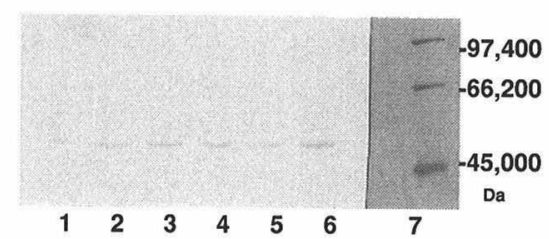

B

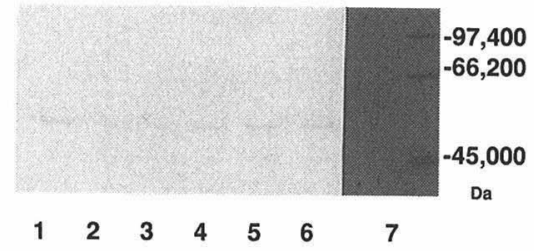

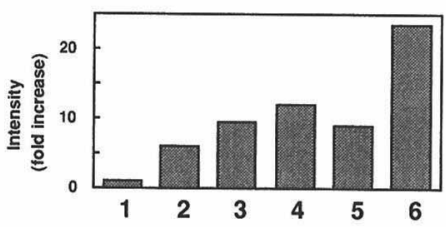

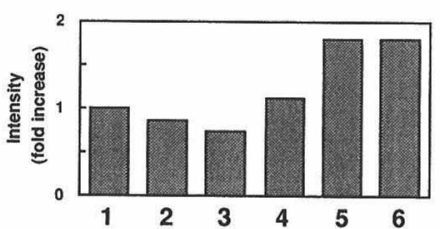

Fig. 3. Western blot analysis of CYP 2E1 (A, upper panel), CYP 1A1 and $1 \mathrm{~A} 2$ (B, upper panel). Hepatic microsomal proteins $(30 \mu \mathrm{g}$ for CYP $2 \mathrm{E} 1$ and $50 \mu \mathrm{g}$ for CYP $1 \mathrm{~A} 1,1 \mathrm{~A} 2)$ of control and garlic groups after oral administration of ethanol were analyzed by immunoblot analysis using monoclonal antibodies (MAb) against EtOH 1-98-1 (A) and MC 1-7-1 (B), respectively. Lane 1 (0 h), lane 2 (1 h) and lane 3 (2 h) contain control microsomes, lane $4(0 \mathrm{~h})$, lane $5(1 \mathrm{~h})$ and lane $6(2 \mathrm{~h})$ contain microsomes of garlic-administered mice, and lane 7 contains molecular weight standards. A densitometric analysis is shown in the lower graphs, A and B, respectively. The intensity of each band was measured by an Image Master and is expressed as 1-fold increase of the values at time 0 of the control.

in the control groups. After ethanol administration, the band of CYP $1 \mathrm{~A} 2$ in the microsomes of the control groups decreased 0.9 -fold $(1 \mathrm{~h})$ and 0.8 -fold $(2 \mathrm{~h})$, while that in the garlic groups increased at $1 \mathrm{~h}$ (1.8-fold) and $2 \mathrm{~h}$ (1.8-fold) (Fig. 3B, lower graph). MAb 1-31-2 (anti-CYP 1A1) and MAb 2-66-3 (anti-CYP 2B1) did not react with any proteins in the hepatic microsomes (data not shown).

Activities of AlDH in the hepatic mitochondria, microsomes and cytosols

In the hepatic mitochondria, the low and high $\mathrm{Km}$ and total AlDH activities showed no significant differences between the control and garlic groups. After ethanol administration, the three AlDHs of the groups also tended to be lower, and the AlDHs of the garlic groups tended to have lower activities than those of the control groups (data not shown).

In the hepatic microsomes, the high $\mathrm{Km}$ and total AlDH activities following garlic administration $(0 \mathrm{~h})$ were significantly higher than those of the control groups. Although the low and high $\mathrm{Km}$ and total AlDHs of the garlic groups tended to decrease at 1 and $2 \mathrm{~h}$ after ethanol administration, there were no significant differences between the AlDH activities of the control and garlic groups (data not shown).

In the hepatic cytosols, the low Km AlDHs did not change either with the 
administration of garlic or over time after the administration of ethanol. Although the high $\mathrm{Km}$ and total AlDH activities of the garlic groups tended to be lower than those of the control groups at 1 and $2 \mathrm{~h}$ after ethanol administration, there were no significant differences between the activities of the groups (data not shown).

\section{DISCUSSION}

Our objective was to examine the combined effects of ethanol and components in fresh garlic on the hepatic ethanol metabolism of mice. Sesamin and related lignan compounds (27) reduce the concentration of plasma ethanol and acetaldehyde in rat more rapidly, and vegetable oils (28) decrease and delay the peak of plasma ethanol concentration in rat. However, in the present study, the rate of disappearance of ethanol from the serum of the control and garlic groups did not significantly differ, although the increase in the concentrations of acetaldehyde and acetate in the serum of the garlic groups tended to be depressed (Fig. 1). These results suggest that some components in the fresh garlic slowed the rate of oxidation of ethanol and accelerated the rate of oxidation of acetaldehyde in the mouse liver. If the oxidation of acetaldehyde in the serum of the garlic groups increased, the concentration of acetate in the serum of the garlic groups should be higher than that of the control groups after ethanol administration. However, the concentration of acetate in the garlic groups tended to be lower than that in the control groups. Therefore, it was inferred that there was no increase in the oxidation of acetaldehyde in the liver following the administration of garlic juice. Cytosolic ADH, which plays the most important role in the ethanol oxidation of liver, increased significantly in the control and garlic groups after ethanol administration, but no difference was found between the activities of the groups (data not shown). It was reported that TAT in the cytosols of rat liver increased after acute ethanol administration (29). In the present study, TAT activities in the livers of the groups of mice increased after ethanol administration, and the TAT activities were not affected by garlic ingestion (data not shown). The activity of MEOS, another pathway from ethanol to acetaldehyde in the hepatic microsomes at $2 \mathrm{~h}$ after ethanol administration, tended to increase in the control groups, whereas it decreased in the garlic groups and showed significantly lower activity than that in the control group (data not shown) The content of cytochrome P-450, which is an indispensable component of MEOS was also depressed in the garlic groups, whereas it increased significantly in the control groups after ethanol administration (Fig. 2). These results suggest that the depression of the increase of concentrations of acetaldehyde in the serum of the garlic groups is due to the depression of the MEOS and cytochrome P-450 induction in hepatic microsomes. The ANH in the hepatic microsomes of the groups tended to increase, and the activity of $\mathrm{ANH}$ in the garlic groups tended to be higher than that of the control groups after ethanol administration, although there were no significant differences between the control and garlic groups (data not shown). Hirose et al reported (30) that, after feeding sesamin, the activity of hepatic cholesterol 
$7 \alpha$-hydroxylase, drug metabolizing enzymes and $\mathrm{ADH}$ remained uninfluenced. Thus, our results are different from those obtained with sesamin.

It was reported that CYP 2E1 showed high ANH activity (11). An immunoreactive band of CYP 2E1, which is the main factor of MEOS, was observed in all preparations of hepatic microsomes, and the intensity of this band following garlic administration $(0 \mathrm{~h})$ increased 12 -fold. The CYP $2 \mathrm{E} 1$ in the hepatic microsomes of the control and garlic groups increased 9.5- and 23.5-fold, respectively, at $2 \mathrm{~h}$ after ethanol administration (Fig. 3A). The hepatic microsomes of the groups also showed high $\mathrm{ANH}$ activities at $2 \mathrm{~h}$ after ethanol administration. It is known that chronic ethanol administration increases the content of cytochrome P-450 and CYP $2 \mathrm{E} 1$ in the hepatic microsomes of mammals, and our data indicate that acute ethanol consumption also increases their concentrations in mice. CYP 2B1 was not detected in any hepatic microsomes. It was reported that DAS inhibited CYP 2E1 in the rat liver $(7,8)$, whereas DAS and its metabolites such as DASO2, and DFS and its metabolites such as DDTC induced CYP 2B1/2 $(9,10)$. However, the garlic juice in the present study did not inhibit CYP 2E1 and did not induce CYP 2B1 in $\mathrm{C} 3 \mathrm{H} / \mathrm{He}$ mouse livers. DAS was given to rats at a dose of $200 \mathrm{mg} / \mathrm{kg}$ of body weight (7). Yu et al reported (3) that monosulfides, disulfides, and trisulfides were the major volatile components among 28 components identified in garlic, and that DAS, diallyl disulfide (DADS) and diallyl trisulfide (DATS) were derived from garlic at $30-100 \mu \mathrm{g} / \mathrm{g}, 530-620 \mu \mathrm{g} / \mathrm{g}$ and $900-1,060 \mu \mathrm{g} / \mathrm{g}$ of garlic bulbs, respectively. It was reported that DADS and allyl methyl sulfide (3.8-4.6 $\mu \mathrm{g} / \mathrm{g}$ garlic bulb) (3), a naturally occurring component of garlic, also inhibited CYP2E1 enzyme activity (31). Thus, our results may have resulted from the fact that our mice were given only small amounts of DAS and other sulfur-containing compounds in the garlic juice. Among xenobiotics metabolized by CYP 2E1 are acetone, acetaminophen, acrylamide, aniline, benzene, butanol, carbon tetrachloride, diethylether, dimethyl sulfoxide, ethyl carbamide, ethylene chloride, halothane, glycerol, ethylene, glycol, $\mathrm{N}$ nitrosodimethylamine, 4-nitrophenol, pyrazole, pyridine, and vinyl chloride (32). The concentration of aniline $(6-11 \mu \mathrm{g} / \mathrm{g}$ bulbs) in garlic is very low (3). Any constituents in the garlic juice which induced CYP 2E1 in the hepatic microsomes of mice were not determined. One immunoreactive band of CYP 1A2 (Fig. 3B) was detected in all hepatic microsomes. This band decreased in the control groups, while it showed 1.8-fold increases at 1 and $2 \mathrm{~h}$ in the garlic grousp after ethanol administration. It seemed that ethanol and some components in the fresh garlic induced CYP 1A2 in hepatic microsomes. These results suggest that the increase of cytochrome P-450 in the control group caused by the increase of CYP 2E1 and some components in the fresh garlic inhibited the induction of the cytochrome P-450 enzymes other than CYP 1A2 and 2E1 after ethanol administration. Kunitoh et al reported that CYP 1A2 also augmented MEOS activity (33). Hamilton and Teel reported that isothiocyanates inhibited the activities of CYP1A1 and 1A2 (34). Although garlic contains 18-25 $\mu \mathrm{g}$ isobutyl isothiocyanate/g bulbs (14), in this study, the garlic juice elevated CYP 1A2. Therefore, none of the constituents in the garlic 
juice which induced CYP 1A2 in the hepatic microsomes of mice were determined. It is interesting that CYP 1A2 was induced in the hepatic microsomes of the garlic groups after ethanol administration, because it is known to be induced by carcinogens, such as 3-methylcholanthrene and benzo[a]pyrene, in hepatic microsomes. Studies of these phenomena are currently in progress in our laboratory. Stoll and Seebeck showed that garlic contains $S$-allylcysteine sulfoxide (alliin) and an enzyme, allinase (2). By the action of allinase on alliin, diallyl thiosulfinate (allicin) is formed, a volatile compound. Semmler established the importance of DADS and DATS in the flavor of garlic (1). It is considered that our fresh garlic juice contained the constituents to be described as follow since it was not centrifuged. In addition to many volatile compounds including organosulfur compounds (3), carbohydrate, protein and fat $(0.9,8.4$ and $0.15 \mathrm{~g} / 100 \mathrm{~g}$ of bulbs, respectively, in Standard Tables of Food Composition in Japan), free sugar such as glucose, fructose and sucrose $(1.2,1.4$ and $7.0 \%$ in bulbs, respectively), minerals related to hepatic drug-metabolism such as $\mathrm{Ca}, \mathrm{Mg}, \mathrm{Fe}, \mathrm{Cu}$ and $\mathrm{Zn}$, and vitamins such as thiamin, riboflavin, nicotinic acid and vitamin $\mathrm{C}$ (35) are contained in garlic juice. Although fructose has been known to increase the rate of ethanol disappearance, the concentration of fructose was low in the garlic juice. Selenium, which is an essential micronutrient, is contained at $0.28 \mu \mathrm{g} / \mathrm{g}$ fresh weight in garlic (36). Ip and Lisk reported that no significant alteration in activity was detected with respect to CYP 1A1, 1A2, 2B1, 2E1 and 3A4 in the livers of control rats and rats fed an Se-garlic supplemented diet (37). Although the concentrations of each mineral in garlic are low, the concentration of total minerals may act on the ethanol metabolism. In conclusion, the factors related to depression of the increase in total cytochrome $\mathrm{P}-450$ in the hepatic microsome of garlic groups after ethanol administration could not be determined in this study.

Acetaldehyde is derived from ethanol though aerobic oxidation by $\mathrm{ADH}$, and is typically rapidly metabolized to acetate by AlDH. Consequently, the acetaldehyde concentrations observed in the blood after ethanol ingestion are generally very low. Hepatic mitochondrial AlDHs, which is the most important enzyme in the acetaldehyde metabolism of liver, tended to decrease after ethanol administration in both control and garlic-administered mice (data not shown). Especially, the hepatic mitochondrial high $\mathrm{Km}$ AlDHs in the control groups decreased significantly after ethanol administration, although there was no significant difference between those of the control and garlic groups. This indicates that a large amount of acute ethanol consumption affects the high $\mathrm{Km}$ AlDHs of the hepatic mitochondrial fraction. The high $\mathrm{Km}$ and total $\mathrm{AlDH}$ in the hepatic microsomes of the garlic groups showed higher activity than those of the control groups (data not shown). The AlDH activities in the microsomes and cytosols of the garlic groups tended to decrease after ethanol administration. The cytosolic low Km AlDHs of the garlic groups were almost the same as those of the control groups (data not shown). In the three fractions, the mitochondria, microsomes and cytosols, the changes in total AlDH activity corresponded closely to the changes in high $\mathrm{Km}$ 
AlDH activity. It seems that the decrease of high $\mathrm{Km}$ and total AlDH activities in the hepatic cytosols diminished the increase of acetate in the serum of the garlic groups after ethanol administration. Yourick and Faiman reported that DSF and its metabolites, DDTC, inhibited cytosolic low and high $\mathrm{Km} \mathrm{AlDH}$ activities (38). Crushed garlic contains more than 35 identical and unidentical volatile compounds including 28 sulfur compounds (3). Some of these sulfur compounds in the garlic juice may have the likely action of DSF. The amino acid sequences of 56 AlDHs from various tissues of humans, other animals, fungi, protozoa and eubacteria are known (39). However the role of these AlDHs in ethanol and acetaldehyde metabolisms is unknown, and the mechanism of the acetaldehyde metabolisms is still unclear. Kunitoh et al (40) reported that CYP 2E1 had the highest oxidation activity, and CYP 1A2 and 4A2 had the next highest activity of NADPH-dependent activity for acetaldehyde oxidation as the microsomal acetaldehyde-oxidizing system in rat liver. Aldehyde oxidase in cytosol and microsome and microsomal aldehyde oxygenase, mainly catalyzed by CYP 2C29 in microsomes (41), could not be determined in this study. It seems that these microsomal enzymes change following garlic administration because the cytochrome P-450 of the hepatic microsome in the garlic groups decreased. Dam et al reported that two mannose-binding lectins (25 and $48 \mathrm{kDa}$ ) from garlic bulbs have been purified (42). However, the effects of these lectins on ethanol metabolism and drug-metabolizing enzymes are not well known. These results indicate that the inhibition of cytochrome P-450 and MEOS in the hepatic microsome of mice by garlic juice after ethanol administration requires a combined effect of multiple, active garlic constituents. Although data at 3 and $4 \mathrm{~h}$ after ethanol administration is required, these results suggest that the ethanol metabolism in the livers of the garlic groups was affected by components of fresh garlic juice, which inactivated some enzymes related to the oxidation of ethanol to acetaldehyde and oxidation acetaldehyde to acetate in the microsomes, as well as the cytosols of the mouse liver. Future studies will be carried out to examine which components in garlic depress the hepatic ethanol metabolism in mice.

This investigation was supported in part by a Grant-in-Aid from the Ministry of Education, Science, Sports and Culture of Japan.

\section{REFERENCES}

1) Semmler FW. 1892. Uber das atherische Ol des knoblauchs (Alliin sativum). Arch Pharm 230: $434-448$.

2) Stoll VA, Seebeck E. 1948. Uber alliin, die genuine muttersubstanz des knoblauchols. Helv Chem Acta 31: 189-210.

3) Yu TH, Wu CM, Liou YC. 1989. Volatile compounds from garlic. J Agric Food Chem 37: 725-730.

4) Belman S. 1983. Onion and garlic oils inhibit tumor formation. Carcinogenesis 4: 1063-1065.

5) Hong JY, Wang ZY, Smith TJ, Zhou S, Shi S, Pan J, Yang CS. 1992. Inhibitory effects 
of diallyl sulfide on the metabolism and tumorigenicity of the tobacco specific carcinogen 4-(methylnitrosamono)-1-(3-pyridyl)-1-butanone (NNK) in A/J mouse lung. Carcinogenesis 13: 901-904.

6) Gudi VA, Singh SV. 1991. Effect of diallyl sulfide, a naturally occurring anti-carcinogen, on glutathione-dependent detoxification enzymes of female CD-1 mouse tissues. Biochem Pharmacol 42: 1261-1265.

7) Brady JF, Li D, Ishizaki H, Yang CS. 1988. Effect of diallyl sulfide on rat liver microsomal nitrosamine metabolism and other monooxygenase activities. Cancer Res 48: $5937-5940$.

8) Chen L, Lee M, Hong J-Y, Huang W, Wang E, Yang CS. 1994. Relationship between cytochrome P450 2E1 and acetone catabolism in rats as studied with diallyl sulfide as an inhibitor. Biochem Pharmacol 48: 2199-2205.

9) Hong JY, Smith T, Lee MJ, Li W, Ma BL, Ning SM, Brady JF, Thomas PE, Yang CS. 1991. Metabolism of carcinogenic nitrosamines by rat nasal mucosa and the effect of diallyl sulfide. Cancer Res 51: 1509-1514.

10) Pan J, Hong JY, Li D, Schuetz EG, Guzelian PS, Huang W, Yang CS. 1993. Regulation of cytochrome P450 2B1/2 genes by diallyl sulfone, disulfiram, and other organosulfur compounds in primary cultures of rat hepatocytes. Biochem Pharmacol 45: 2323-2329.

11) Koop DR, Morgan ET, Tarr GE, Coon MJ. 1982. Purification and characterization of a unique isozyme of cytochrome P-450 from liver microsomes of ethanol-treated rabbits. J Biol Chem 257: 8472-8480.

12) Lieber CS, DeCarli LM, Matsuzaki S, Ohnishi K, Teschke R. 1997. The microsomal ethanol oxidizing system (MEOS). In: Biomembranes, Selected Methods in Enzymology Series (Packer L, Fleischer S, eds), p 329-341, Academic Press, New York and London.

13) Terelius Y, Norsten-Hoog C, Cronholm T, Ingelman-Sundberg M. 1991. Acetaldehyde as a substrate for ethanol-inducible cytochrome P450 (CYP 2E1). Biochem Biophys Res Commun 179: 689-694.

14) Tschanz C, Stargel WW, Thomas JA. 1996. Interactions between drugs and nutrients. Adv Pharmacol 35: 1-26.

15) Kishimoto R, Fujiwara I, Kitayama S, Goda K, Nakata Y. 1995. Changes in hepatic enzyme activities related to ethanol metabolism in mice following chronic ethanol administration. J Nutr Sci Vitaminol 41: 527-543.

16) Kishimoto R, Ueda M, Kawakami M, Goda K, Park SS, Nakata Y. 1997. Effect of chronic administration of alcoholic beverages and seasoning containing alcohol on hepatic ethanol metabolism in mice. J Nutr Sci Vitaminol 43: 613-626.

17) Granner DK, Tomkins GM. 1970. Tyrosine aminotransferase (rat liver). In: Methods in Enzymology (Tabor H, Tabor CW, eds), XVII Part A, p 633-637. Academic Press, New York and London.

18) Klein SM, Gohen G, Lieber CS, Cederbaum AI. 1983. Increased microsomal oxidation of hydroxyl radical scavenging agents and ethanol after chronic consumption of ethanol. Arch Biochem Biophys 223: 425-432.

19) Brodie BB, Axelrod J. 1948. The estimation of acetanilide and its metabolic products, aniline, $N$-acetyl $p$-aminophenol and $p$-aminophenol (free and total conjugated) in biological fluids and tissues. $J$ Pharmacol Exp Ther 94: 22-28.

20) Lebsack ME, Gordon ER, Lieber CS. 1981. Effect of chronic ethanol consumption on aldehyde dehydrogenase activity in the baboon. Biochem Pharmacol 30: 2273-2277.

21) Ko I-Y, Park SS, Song BJ, Patten C, Tan Y, Hah YC, Yang CS, Gelboin HV. 1987. Monoclonal antibodies to ethanol-induced rat liver cytochrome P-450 that metabolizes aniline and nitrosamines. Cancer Res 47: 3101-3109.

22) Park SS, Fujino T, West D, Guengerich FP, Gelboin HV. 1984. Monoclonal antibodies that inhibit enzyme activity of 3-methylcolanthene-induced cytochrome P-450. Cancer

Vol 45, No 3, 1999 
Res 42: 1798-1808.

23) Park SS, Fugino T, West D, Guengerich FP, Gelboin HV. 1984. Monoclonal antibodies to phenobarbital-induced rat liver cytochrome P-450. Biochem Pharmacol 33: 2071-2081.

24) Omura T, Sato R. 1964. The carbon monooxide-binding pigment of liver microsomes. J Biol Chem 239: 2370-2378.

25) Gornall AG, Bardawill CJ, David MM. 1948. Determination of serum proteins by means of biuret reaction. $J$ Biol Chem 177: 751-766.

26) Duncan DB. 1957. Multiple range tests for correlated and heteroscedastic means. Biometrics 13: 164-176.

27) Akimoto K, Shimizu S. 1994. Unique function of sesamin and related lignans in alcohol metabolism. J Brew Soc Jpn 89: 787-792.

28) Tachiyashiki K, Imaizumi K. 1993. Effects of vegetable oils and $\mathbf{C}_{18}$-unsaturated fatty acids on plasma ethanol levels and gastric emptying in ethanol-administered rats. $J$ Nutr Sci Vitaminol 39: 163-176.

29) Badawy AA-B, Snape BM, Evans M. 1980. Biphasic effect of acute ethanol administration on rat liver tyrosine-2-oxoglutarate aminotransferase activity. Biochem $J$ 186: $755-761$.

30) Hirose N, Inoue T, Nishihara K, Sugano M, Akimoto K, Shimizu S, Yamada H. 1991. Inhibition of cholesterol absorption and synthesis in rats by sesamin. $J$ Lipid Res 32: 629-638.

31) Reicks MM, Crankshaw DL. 1996. Modulation of rat hepatic cytochrome P-450 activity by garlic organosulfur compounds. Nutr Cancer 25: 241-248.

32) Guengerich FP, Kim DH, Iwasaki M. 1991. Role of human cytochrome P-450 IIE1 in the oxidation of many low molecular weight cancer suspects. Chem Res Toxicol 4: $168-179$.

33) Kunitoh S, Tanaka T, Imaoka S, Funae Y, Monna Y. 1993. Contribution of cytochrome P450s to MEOS (microsomal ethanol-oxidizing system): A specific and sensitive assay of MEOS activity by HPLC with fluorescence labeling. Alcohol Alcohol 28: 63-68.

34) Hamilton SM, Teel RW. 1996. Effects of isothiocyanates on cytochrome P-450 1A1 and $1 \mathrm{~A} 2$ activity and on the mutagenicity of heterocyclic amines. Anticancer Res 16: 3597-3602.

35) Fenwick GR, Hanley AB. 1985. The genus Allium. Part 2. Crit Rev Food Sci Nutr 22: 273-377.

36) Morris VC, Levander OA. 1970. Selenium content of foods. J Nutr 100: 1383-1388.

37) Ip C, Lisk DJ. 1997. Modulation of phase I and phase II xenobiotic-metabolizing enzymes by selenium-enriched garlic in rats. Nutr Cancer 28: 184-188.

38) Yourick JJ, Faiman MD. 1989. Comparative aspects of disulfiram and its metabolites in the disulfiram-ethanol reaction in the rat. Biochem Pharmacol 38: 413-421.

39) Yoshida A, Rzhetsky A, Hsu LC, Chang C. 1998. Human aldehyde dehydrogenase gene family. Eur $J$ Biochem 251: 549-557.

40) Kunitoh S, Asai H, Imaoka S, Funae Y, Monna T. 1996. Metabolism of acetaldehyde to acetate by rat hepatic P-450s: presence of different metabolic pathway from acetaldehyde dehydrogenase system. Alcohol Clin Exp Res 20 (1 suppl): 22A-24A.

41) Matsunaga T, Iwawaki Y, Watanabe K, Yamamoto I, Kageyama T, Yoshimura H. 1996. Microsomal aldehyde oxygenase (MALDO): purification and characterization of a cytochrome $\mathrm{P} 450$ isozyme responsible for oxidation of 9-anthraldehyde to 9-anthracenecarboxylic acid in monkey liver. $J$ Biochem 119: 617-625.

42) Dam TK, Bachhawat K, Rani PG, Surolia A. 1998. Garlic (Allium sativum) lectins bind to high mannose oligosaccharide chains. J Biol Chem 273: 5528-5535. 